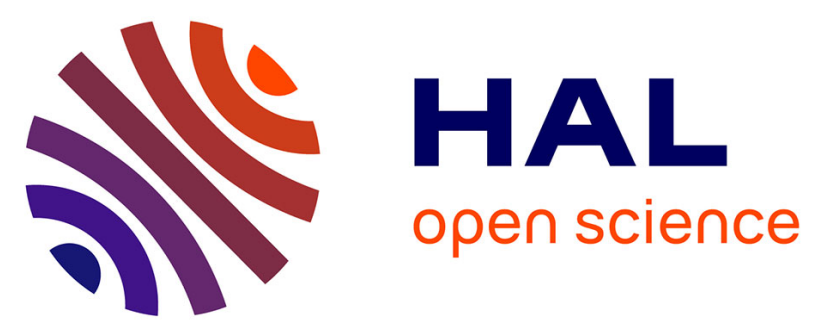

\title{
A Versatile Iridium(III) Metallacycle Catalyst for the Effective Hydrosilylation of Carbonyl and Carboxylic Acid Derivatives
}

Yann Corre, Vincent Rysak, Xavier Trivelli, Francine Agbossou-Niedercorn, Christophe Michon

\section{To cite this version:}

Yann Corre, Vincent Rysak, Xavier Trivelli, Francine Agbossou-Niedercorn, Christophe Michon. A Versatile Iridium(III) Metallacycle Catalyst for the Effective Hydrosilylation of Carbonyl and Carboxylic Acid Derivatives. European Journal of Organic Chemistry, 2017, 2017 (32), pp.4820-4826. 10.1002/ejoc.201700801 . hal-01715048

\author{
HAL Id: hal-01715048 \\ https://hal.science/hal-01715048
}

Submitted on 31 Aug 2020

HAL is a multi-disciplinary open access archive for the deposit and dissemination of scientific research documents, whether they are published or not. The documents may come from teaching and research institutions in France or abroad, or from public or private research centers.
L'archive ouverte pluridisciplinaire HAL, est destinée au dépôt et à la diffusion de documents scientifiques de niveau recherche, publiés ou non, émanant des établissements d'enseignement et de recherche français ou étrangers, des laboratoires publics ou privés. 


\title{
A versatile iridium(III) metallacycle catalyst for the effective hydrosilylation of carbonyl and carboxylic acid derivatives.
}

\author{
Yann Corre, ${ }^{[a, b]}$ Vincent Rysak, ${ }^{[a, b]}$ Xavier Trivelli, ${ }^{[c]}$ Francine Agbossou-Niedercorn ${ }^{\star[a, b]}$ and Christophe \\ Michon*[a,b]
}

\begin{abstract}
A versatile iridium(III) metallacycle catalyses rapidly and selectively the reduction of a large array of challenging esters and carboxylic acids as well as various ketones and aldehydes. Reactions proceed with high yields at room temperature through hydrosilylation followed by desilylation. Whether the reaction of various aldehydes and ketones results exclusively in alcohols, the hydrosilylation of esters leads to alcohols or ethers depending on the type of substrate. Regarding the carboxylic acids, the nature of the reagent controls also the outcome of the hydrosilylation reaction, either alcohols or aldehydes being formed.
\end{abstract}

\section{Introduction}

The use of hydrosilanes as reductants is an area of growing interest for the mild and selective reduction of carboxylic acid derivatives by using transition metal or Lewis acid catalysts. ${ }^{[1,2]}$ Indeed, hydrosilylation, which operates without any high pressure equipment and high temperature, can be an interesting alternative to hydrogenation, provided that inexpensive and abundant hydrosilanes are used. Because the reactivity of such reagents and related reaction intermediates is modular and depends on the substituents of the silicon atoms, the hydrosilylation reaction can become a highly chemo- and regioselective reduction method which tolerates various other reducible functional groups. ${ }^{[2]}$ However, whereas several organometallic or organic catalysts were shown to hydrosilylate aldehydes and ketones, ${ }^{[2-5]}$ the hydrosilylation of less reactive substrates like hindered ketones, ${ }^{[6]}$ carboxylic acids ${ }^{[7]}$ and esters $^{[8,9]}$ remains challenging (Scheme 1). Whether several iridium catalysts were effective for the hydrosilylation of carbonyl compounds (e.g. aldehydes and ketones ${ }^{[3]}$ and carbon-carbon multiple bonds, ${ }^{[10]}$ their applications in the reduction of carboxylic acid derivatives ${ }^{[11]}$ and $\mathrm{CO}_{2}{ }^{[12]}$ remain almost unexplored. Moreover, to the best of our knowledge, only iridium(III) POCOP (i.e. 2,6-bis(di-tert-butylphosphinito)phenyl) catalyst has proved to be versatile for the effective hydrosilylation of a large array of carbonyl and carboxylic acid substrates. ${ }^{[3,11 b]}$ Following our previous studies on hydrosilylation reactions of unsaturated

[a] Dr. Y. Corre, V. Rysak, Dr. F. Agbossou-Niedercorn, Dr. C. Michon, Univ. Lille, CNRS, Centrale Lille, ENSCL, Univ. Artois, UMR 8181 UCCS - Unité de Catalyse et Chimie du Solide, F-59000 Lille, France. E-mail: christophe.michon@ensc-lille.fr,

francine.agbossou@ensc-lille.fr

Homepages: http://uccs.univ-lille1.fr/index.php/annuaire/15-fichespersonnels/221-michon-christophe

http://uccs.univ-lille1.fr/index.php/annuaire/15-fiches-personnels/81agbossou-niedercorn-francine

[b] ENSCL, UCCS-CCM-MOCAH, (Chimie-C7) CS 90108, 59652 Villeneuve d'Ascq Cedex, France

[c] Dr. X. Trivelli, UGSF CNRS, UMR 8576, Université Lille Nord de France, 59655 Villeneuve d'Ascq Cedex, France.

Supporting information for this article is available on the web. carbon-carbon and carbon-heteroatom compounds using iridium(III) metallacycle catalysts, ${ }^{[13]}$ we have recently reported on the challenging hydrosilylation of amides ${ }^{[13 \mathrm{e}]}$ and esters. ${ }^{[13 \mathrm{~d}]}$ In the latter case, the combination of a cationic iridium(III) metallacycle and 1,3,5-trimethoxybenzene allows the rapid and selective reduction of esters to aldehydes at room temperature with high yields through hydrosilylation followed by hydrolysis (Scheme 1). The ester reduction involves the trapping of transient silyl cations by the 1,3,5-trimethoxybenzene cocatalyst, supposedly by formation of an arenium intermediate whose role was addressed by DFT calculations. Herein, we report the same accessible iridium(III) metallacycle catalyses rapidly and selectively the reduction of a large array of carboxylic acids, esters, ketones and aldehydes with high yields at room temperature through hydrosilylation followed by desilylation (Scheme 1).

Order of reactivity for the hydrosilylation of carbonyl functions:<smiles></smiles>

Previous work:

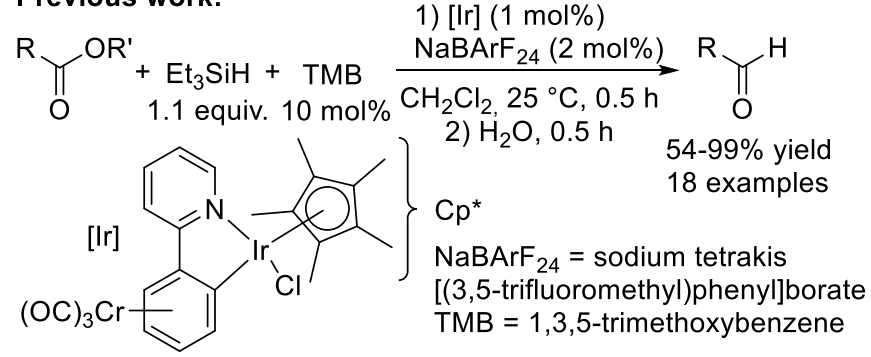

This report:

$\left\{\begin{array}{c}\text { carboxylic acid } \\ \text { or ester } \\ \text { or ketone } \\ \text { or aldehyde }\end{array}\right\}+$ silane $\frac{\begin{array}{c}\text { 1) }[\mathrm{Ir}](0.1-1 \mathrm{~mol} \%) \\ \mathrm{NaBArF}_{24}(0.2-2 \mathrm{~mol} \%)\end{array}}{\mathrm{CH}_{2} \mathrm{Cl}_{2}, 25{ }^{\circ} \mathrm{C}} \begin{gathered}\text { alcohol } \\ \text { 2) desilylation }\end{gathered}$
$\begin{gathered}\text { or ether } \\ \text { or aldehyde to } 99 \% \text { yield } \\ 56 \text { examples }\end{gathered}$ metallacycle.

\section{Results and Discussion}

\section{Hydrosilylation of aldehydes}

Iridium(III) metallacycle pre-catalyst [Ir], sodium tetrakis[(3,5-trifluoromethyl)phenyl]borate $\quad\left(\mathrm{NaBArF}_{24}\right)$ additive and reaction conditions (e.g. silane, solvent, temperature) initially used for the reduction of esters into aldehydes (Scheme 1) were applied for the hydrosilylation of a series of aldehydes (Table 1). The corresponding alcohols were recovered in excellent isolated yields from the silylether products through desilylation with tetrabutylammonium fluoride (TBAF). Catalyst and $\mathrm{NaBArF}_{24}$ loadings were decreased to respectively 0.1 and 
$0.2 \mathrm{~mol} \%$ as the reactions were still performing well without any decrease of activity. The hydrosilylation of aromatic substrates 1a-b was completed with 5 minutes (entries 1, 2 ). Whether furan 2 -carbaldehyde $1 \mathrm{c}$ reacted readily (entry $3)$, the hydrosilylation of thiophene 2-carbaldehyde 1d required 2 hours to go to completion (entry 4). By comparison, the more coordinating pyridine analogue $\mathbf{1 e}$ reacted barely in $24 \mathrm{~h}$ (entry 5). Hydrosilylation of orthoand para- substituted benzaldehydes 1f-i was straightforward independently of the substitution pattern of the substrate (entries 6-9). Finally, alkyl aldehydes 1j-I were also readily reduced in 5 to 60 minutes (entries 10-12).

\section{Hydrosilylation of ketones}

The same catalytic system was subsequently used for the hydrosilylation of ketones $\mathbf{3 a - I}$ (Table 2). The resulting alcohols 4a-I were retrieved in average to excellent isolated yields after hydrolysis or desilylation with TBAF. At 2 exceptions, catalyst and additive loadings of 0.5 and 1 mol\% allowed all reactions to proceed in few hours. Benzophenone $\mathbf{3 a}$, acetophenone $\mathbf{3} \mathbf{b}$ and acetonaphtone $3 c$ were readily reduced in 2 hours (entries 1-3). However, the hydrosilylation of 2-acetylpyridine $\mathbf{3 d}$ proved to be harder most likely because of a possible catalyst inhibition through substrate chelation (entry 4). Reactions of other aromatic and alkyl ketones $3 \mathbf{e}-\mathbf{h}$ proceeded also well in 2 to 4 hours (entries 5-8). Moreover, the hydrosilylation of more challenging substrates like sterically hindered ketones ${ }^{[6]}$ was not a limitation. Indeed, the reductions of pivalophenone $\quad 3 \mathbf{i}, \quad 2$-acetylmesitylene $\quad 3 \mathbf{j}$ and dicyclohexylmethanone $\mathbf{3 k}$ were straightforward and proceeded in few hours (entries 9-11). However, the hydrosilylation of diisopropylmethanone $\mathbf{3 l}$ proved to be harder requiring a reaction temperature of $40^{\circ} \mathrm{C}$ and a longer reaction time to go to completion (entry 12 ).

Table 1. Hydrosilylation of aldehydes 1a-I.

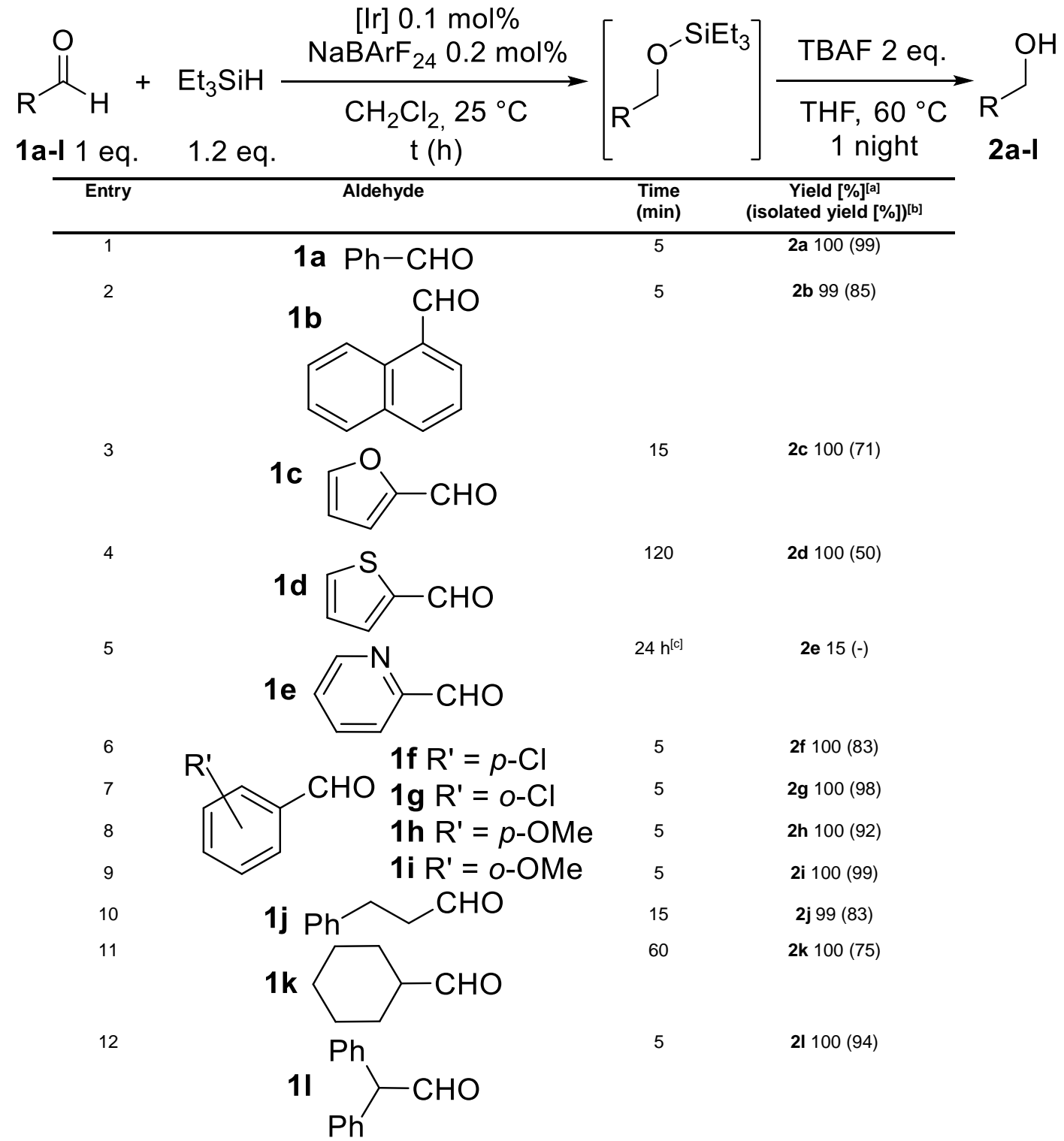

[a] Yield in silyl ether determined by ${ }^{1} \mathrm{H}$ NMR. [b] Isolated yield in alcohols 2a-I after desilylation with TBAF and purification. [c] Temperature $=40{ }^{\circ} \mathrm{C}$. Table 2. Hydrosilylation of ketones 3a-I into alcohols 4a-I. 


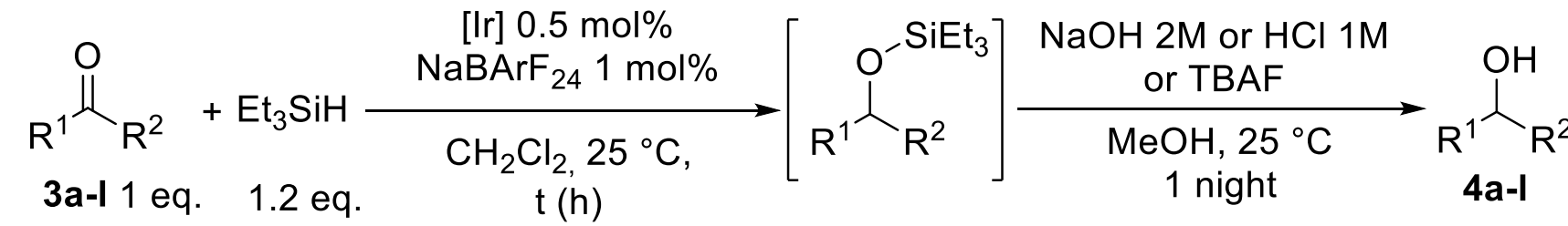

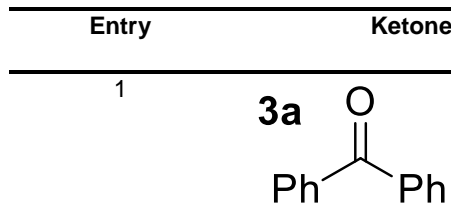

2

$3 b$

b $\mathrm{O}$

[[c]

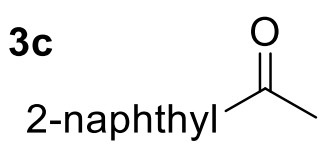<smiles>CC(=O)c1ccccn1</smiles>

5<smiles>CCCC(=O)c1ccccc1-c1ccccc1C(=O)CC</smiles>

7

10<smiles>O=C(Cc1ccccc1)c1ccccc1</smiles><smiles>CC(=O)CC[SnH2]</smiles><smiles>CC(C)(C)[As]C(=O)c1ccccc1</smiles>

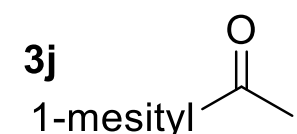

11

12<smiles>CC(C)C(=O)C(C)C</smiles>

Yield [\%] ${ }^{[\mathrm{a}]}$
(isolated yield [\%] $^{[\mathrm{b}}$

4a 100 (54)

4b 100 (55)

4c 100 (86)

4d $33(-)$

4e 100 (99)

4f 100 (78)

4g 100 (89)

4h 89 (53)

4i 97 (87)

4j 77 (51)

4k $100(64)$

4l $100(-)^{[d]}$

[a] Yield in silylether determined by ${ }^{1} \mathrm{H}$ NMR. [b] Isolated yield in alcohols 4a-l, after hydrolysis or desilylation with TBAF and purification. [C] Catalyst loading $=1 \mathrm{~mol} \%$ and temperature $=40^{\circ} \mathrm{C}$. [d] at $40^{\circ} \mathrm{C}$ because no reaction in 3 hours at $25^{\circ} \mathrm{C}$. 
Table 3. Hydrosilylation of esters 5a-p into alcohols 6a-p and ethers 7a-p.

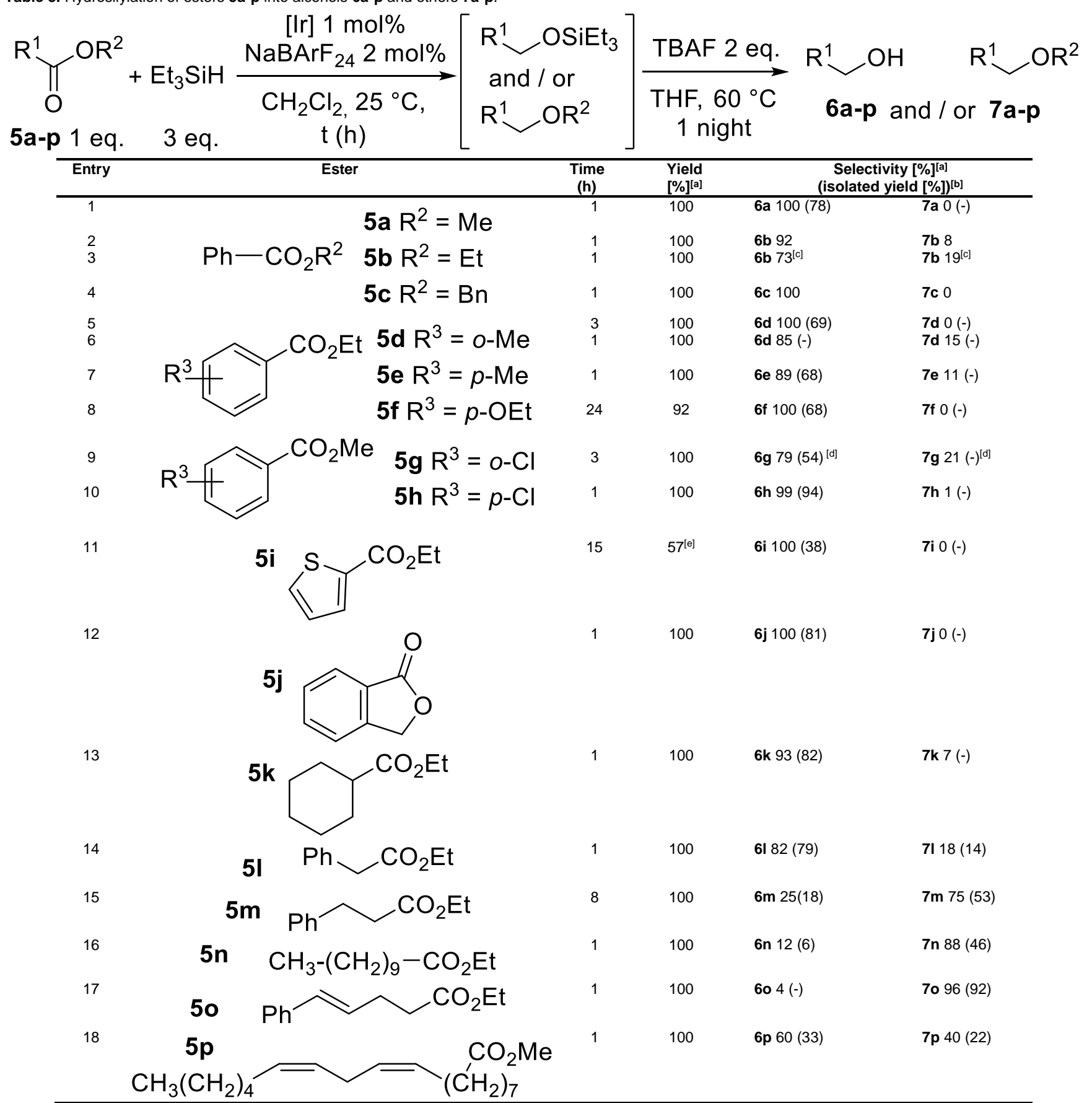

[a] Yield determined by ${ }^{1} \mathrm{H}$ NMR. [b] Isolated yields in alcohols 6a-p or ethers 7a-p after desilylation with TBAF and purification. [c] for 2 eq. Et ${ }_{3} \mathrm{SiH}$ with benzaldehyde (8\%) as a side product. [d] Same ratio alcohol / ether at $\mathrm{t}=6$ hours. [e] Temperature $=60^{\circ} \mathrm{C}$ and solvent $=\mathrm{TCE}$.

\section{Hydrosilylation of esters}

Next, the same catalytic system was applied for the hydrosilylation of esters (Table 3 ). Though these reductions were known to be more difficult, ${ }^{[8,9]}$ most of the reactions proceeded well with iridium(III) metallacycle pre-catalyst [Ir] and $\mathrm{NaBArF}_{24}$ additive loadings respectively of 1 and 2 $\mathrm{mol} \%$. Alcohols 6a-p and/or alkyl ethers 7a-p were obtained with variable selectivities and moderate to high isolated yields depending on the molecular structure of the substrate. Similarly to aldehydes and some ketones, the alcohol products were obtained through desilylation of the related silylethers with tetrabutylammonium fluoride (TBAF). We noticed the use of 3 equivalents of triethylsilane (entries 2,3 ) or of a longer reaction time (entries 5,6) could enhance the reaction selectivity for alcohols by reducing significantly the amount of formed alkyl ethers. Brookhart et al. previously reported iridium(III) POCOP catalyst could cleave alkyl ethers into silylated alcohols and alkanes using triethylsilane. ${ }^{[14]}$ 
Table 4. Hydrosilylation of carboxylic acids $8 \mathrm{a}-\mathrm{p}$ into alcohols $9 \mathrm{a}-\mathrm{f}, \mathrm{m}-\mathrm{p}$ or aldehydes $\mathbf{1 0 g}-\mathbf{I}$.

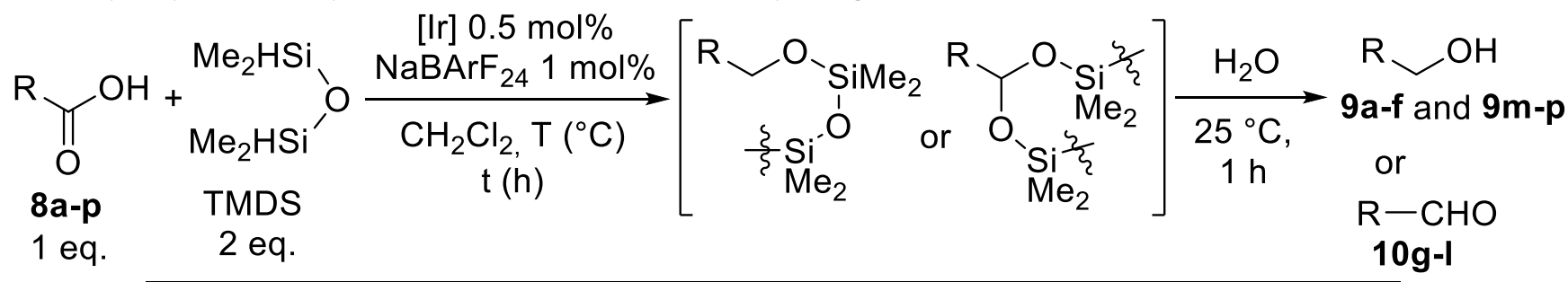

\begin{tabular}{|c|c|c|c|c|}
\hline Entry & Carboxylic acid & $t(h)$ & $\mathrm{T}\left({ }^{\circ} \mathrm{C}\right)$ & 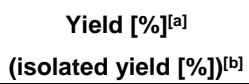 \\
\hline 1 & $8 \mathbf{a} \mathrm{Ph}-\mathrm{CO}_{2} \mathrm{H}$ & 15 & 40 & 9a $100(67)$ \\
\hline 2 & $8 \mathbf{b ~ P h} \mathrm{CO}_{2} \mathrm{H}$ & 5 & 25 & 9b $100(90)$ \\
\hline 3 & & 15 & 40 & $9 c 100(68)$ \\
\hline $\begin{array}{c}4 \\
5^{[c]}\end{array}$ & $\mathrm{O}_{2} \mathrm{H}$ & $\begin{array}{l}5 \\
5\end{array}$ & $\begin{array}{l}25 \\
25\end{array}$ & $\begin{array}{l}9 \mathbf{d} 100(83) \\
9 \mathbf{d} 16(-)\end{array}$ \\
\hline 6 & $\mathrm{O}_{2} \mathrm{H}$ & 15 & 25 & 9e 100 (84) \\
\hline 7 & & 15 & 25 & 9f $100(77)$ \\
\hline 8 & $8 \mathrm{~g}$ & 5 & 25 & $\log 100$ (83) \\
\hline 9 & $8 h$ & 15 & 40 & 10h 100 (88) \\
\hline 10 & $8 i R^{\prime}=0-F$ & 15 & 40 & 10i $100(83)$ \\
\hline 11 & $8 \mathbf{j} \mathrm{R}^{\prime}=p-\mathrm{F}$ & 15 & 40 & 10j 100 (79) \\
\hline 12 & $8 k R^{\prime}=0-C l$ & 15 & 40 & 10k $100(79)$ \\
\hline 13 & $81 R^{\prime}=p-B r$ & 15 & 40 & $101100(81)$ \\
\hline 14 & $8 \mathrm{~m} \mathrm{R}^{\prime}=p-\mathrm{NO}_{2}$ & 15 & 40 & $9 m 36(26)$ \\
\hline 15 & $8 \mathrm{n} \mathrm{R}^{\prime}=p-\mathrm{OMe}$ & 15 & 40 & 9n $100(93)$ \\
\hline 16 & $80 R^{\prime}=0-O M e$ & 40 & 40 & 90100 (74) \\
\hline 17 & $8 p$ & 15 & 40 & $9 p 100(60)$ \\
\hline 18 & $8 q$ & 24 & 40 & $0^{[d]}$ \\
\hline
\end{tabular}

[a] Yield measured by ${ }^{1} \mathrm{H}$ NMR. [b] Isolated yields in alcohols $9 \mathrm{a}-\mathrm{f}$ and $\mathbf{9 m - p}$ or aldehydes $\mathbf{1 0 g - I}$ after hydrolysis and purification [c] with 4 eq. Et ${ }_{3} \mathrm{SiH}$. [d] Same result in 24 hours at $80^{\circ} \mathrm{C}$ in TCE.

According the present results, iridium(III) metallacycles catalysed a similar ether cleavage depending on the substrate basicity. Although aromatic ethers $\mathbf{7 b}$ and $\mathbf{7 d}$ were converted to alcohols $\mathbf{6 b}$ and $\mathbf{6 d}$ (entries 2,3,5,6), alkyl ethers $\mathbf{7 m}$ and 70 remained unreacted (entries 15,17). The reaction of benzoate derivatives $5 a-c$ led to benzyl alcohol independently of the nature of the $R^{2}$ substituent (entries 1-4). Hydrosilylation of ortho- and para- substituted benzoates $\mathbf{5 d - e}$ and $\mathbf{5 g}-\mathbf{h}$ was straightforward to the related alcohols as the main products without any effect of the substitution pattern of the reagent (entries 5-7,9-10). However, the para- substitution by an ethoxy group led to a less reactive substrate $\mathbf{5 f}$ which was fully reduced in 24 hours (entry 8 ). 
Similarly, the hydrosilylation of thiophene derivative $5 \mathbf{i}$ proved to be difficult, a reaction of 15 hours being required to obtain the related alcohol in an average yield (entry 11). Interestingly, the reaction of lactone $\mathbf{5 j}$ led effectively to the related 1,2-phenylenedimethanol (entry 12). Whether the hydrosilylation of cyclohexyl and benzyl ethyl esters 5k-I afforded alcohols as the major products (entries 13-14), the reaction of other alkyl substrates $5 \mathrm{~m}-0$ resulted predominantly in the related ethyl ethers (entries 15-17), probably due to their longer alkyl chains and their less sterically hindered structures. Finally, the hydrosilylation of methyllinoleate $5 p$ was far less selective resulting in the corresponding alcohol along with significant amount of the methyl ether product (entry 18).

\section{Hydrosilylation of carboxylic acids}

Since the catalytic system was found to be effective in the hydrosilylation of esters, we subsequently studied the more challenging reduction of carboxylic acids (Table 4). ${ }^{[7]}$ Whether iridium(III) metallacycle pre-catalyst and $\mathrm{NaBArF}_{24}$ additive loadings were reduced to respectively 0.5 and $1 \mathrm{~mol} \%$, the change of triethysilane for 1,1,3,3-tetramethyldisiloxane (TMDS) proved to be critical to allow the hydrosilylation to proceed (entries 4,5). We noticed also an increase of the reaction temperature to $40^{\circ} \mathrm{C}$ was often required to recover products in high yields. Hydrolysis of the resulting silyl ethers or acetals to the corresponding alcohols or aldehydes could be performed by simple addition of water to the reaction mixture. Indeed, hydration of the remaining $0.5 \mathrm{~mol} \%$ of $\mathrm{NaBArF}_{24}$ resulted in a catalysis producing a Brønsted acid, which could cleave chemoselectively the generated silyl acetals. ${ }^{[13 d, 15]}$ On the whole, we obtained selectively alcohols $\mathbf{9 a - f , m - p}$ or aldehydes $\mathbf{1 0 g}-\mathrm{I}$ in good to high isolated yields depending on the molecular structure of the substrate. The hydrosilylation of benzoic acid $8 \mathrm{a}$ and 2-thiophene acetic acid $8 \mathbf{c}$ required 15 hours of reaction at $40^{\circ} \mathrm{C}$ to afford the related alcohols (entries 1,3 ). By comparison, the reaction of phenylacetic acid $\mathbf{8} \mathbf{b}$ and 3 -phenylpropionic acid $\mathbf{8 d}$ were faster, alcohols $\mathbf{9 b}$ and $9 \mathrm{~d}$ being obtained in only 5 hours at $25^{\circ} \mathrm{C}$ (entries 2, 4). However, alkyl substrates $8 \mathrm{e}$ and $8 \mathbf{f}$ needed 15 hours to lead to the corresponding alcohols (entries $6,7)$. To our surprise, the hydrosilylation of 2-phenylpropanoic acid $\mathbf{8 g}$ and diphenylacetic acid $\mathbf{8 h}$ afforded aldehydes $\mathbf{1 0 g}-\mathbf{h}$ (entries 8, 9). Whether a similar trend was observed for halogenated benzoic acids 8i-I (entries 10-13),

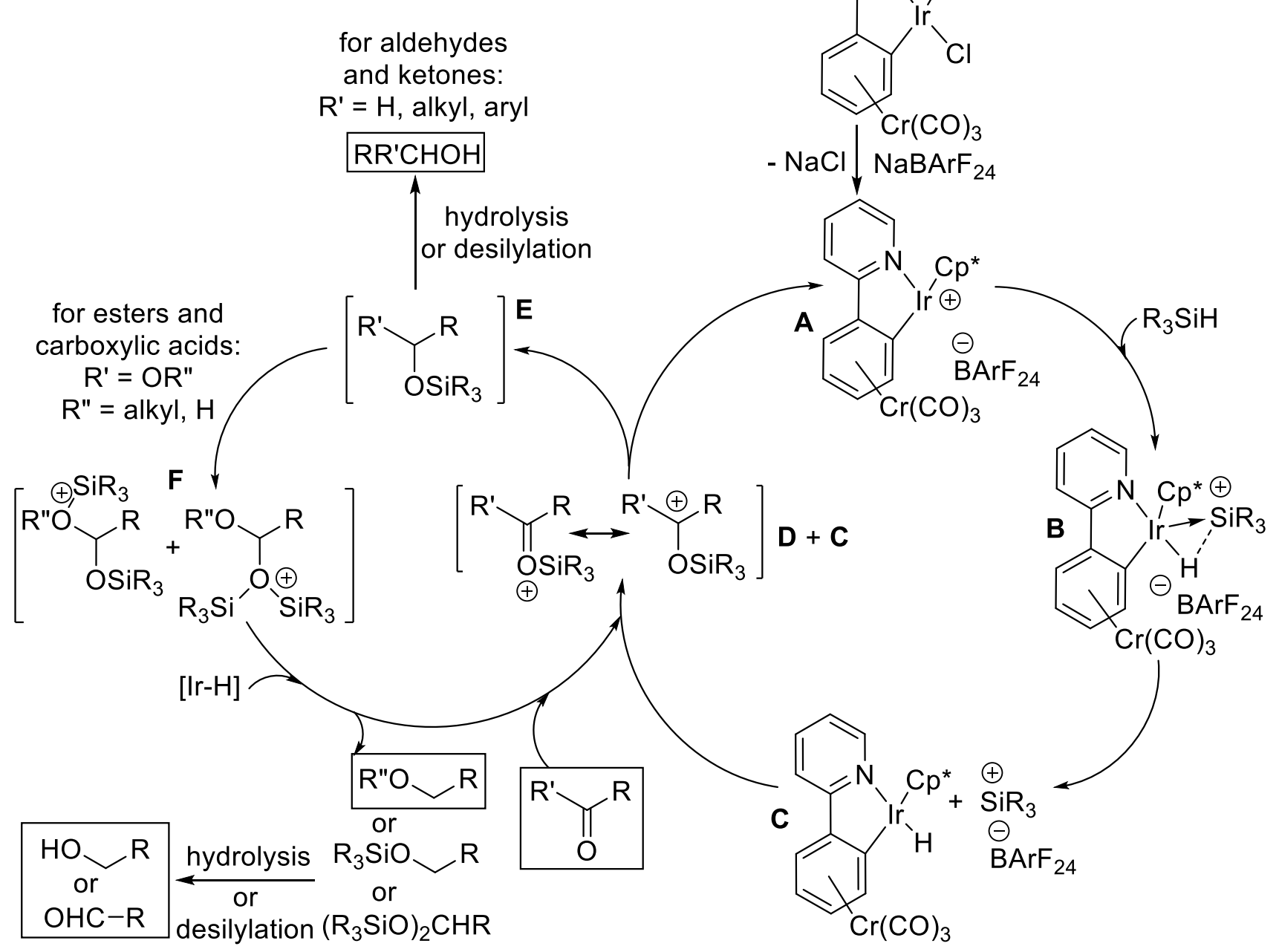

Scheme 2. Reaction mechanism proposal. 
the reaction of other electron poor substrates like paranitrobenzoic acid $8 \mathrm{~m}$ and 2-bromo-2-phenylacetic acid $8 \mathrm{p}$ led to alcohols $9 \mathrm{~m}$ and $9 \mathrm{p}$ (entries 14,17 ). If the hydrosilylation of para-methoxybenzoic acid $8 \mathrm{n}$ was rather straightforward to the alcohol 9n (entry 15), ortho-methoxybenzoic acid 80 was far less reactive probably due to its chelation to the catalyst (entry 16). Such inhibition effect was confirmed by the unreactivity of pyridine-2-carboxylic acid $\mathbf{8 q}$, a stronger chelate which prevented any reaction to occur (entry 18).

\section{Reaction mechanism}

Regarding the reaction mechanism, an ionic hydrosilylation ${ }^{[14,16]}$ pathway could be presumed. Djukic et al. have already shown through a combination of organometallic syntheses and DFT calculations a cohesive hydridoiridium(III) $\rightarrow$ silylium donor-acceptor complex could exist. ${ }^{[17]}$ Hence, we assumed our reaction pathway could differentiate from the others involving iridium catalysts ${ }^{[2,16]}$ by the activation mode of the silane. At first, precatalyst is dehalogenated by $\mathrm{NaBArF}_{24}$ to give a transient cationic complex A (Scheme 2) which was observed by ESI-MS during the analysis of a reaction crude mixture (Figure $S 1$ in the Supporting Information). ${ }^{[13 a, e]}$ The iridium catalyst activates the silane reagent through the formation of a silane-iridium adduct B. ${ }^{[16,17]}$ Such an activation process would produce an iridium hydride complex $\mathbf{C}^{[18]}$ and a silyl cation. ${ }^{[19]}$ The latter may activate the carbonyl group of the substrate and generate a silyloxy carbonium species $\mathbf{D}$, which can be stabilised by an electron-donating group R'. Reaction with a first equivalent of the iridium hydride complex $\mathbf{C}$ affords silyl intermediate $\mathbf{E}$ along with the cationic iridium catalytic species $\mathbf{A}$. At that stage, several pathways are possible depending on the nature of the substrate. In the case of aldehydes and ketones, a further hydrolysis or desilylation of silyl ether $\mathbf{E}$ offers the alcohol product. Concerning the hydrosilylation of carboxylic acids 8a-p or esters 5a-p, the silyl intermediate $\mathbf{E}$ can react further through activation of its ether or hydroxy groups by silyl cation and formation of intermediates $\mathbf{F}$. After reaction with a second equivalent of iridium hydride complex $\mathbf{C}$, alkylether, silylether or acetal products are either formed along with the release of the catalytic cationic iridium species $\mathbf{A}$ and a final hydrolysis or desilylation step affords the organic product as an alcohol, ether or aldehyde.

Concerning the hydrosilylation of esters $5 \mathbf{a}-\mathbf{p}$, alcohols $\mathbf{6 a -}$ $\mathbf{p}$ and/or ethers 7a-p are obtained depending on the nature of the substrates and their steric hindrance. Although aromatic and sterically hindered esters are mainly reduced to alcohols, linear alkyl esters are converted to ethers. Moreover, iridium(III) metallacycle catalyst can cleave alkyl ether ${ }^{[14]}$ into silylated alcohols and alkanes depending on the substrate basicity. Although aromatic ethers $\mathbf{7 b}$ and $\mathbf{7 d}$ were converted to alcohol $6 \mathrm{~b}$ and $6 \mathrm{~d}$, alkyl ethers $7 \mathrm{~m}$ and 70 remained unreacted.

Regarding the hydrosilylation of carboxylic acids, alcohols $\mathbf{9 a}-\mathbf{f}, \mathbf{m}-\mathbf{p}$ or aldehydes $\mathbf{1 0 g}-\mathrm{I}$ are obtained selectively after a subsequent hydrolysis, without any defined influence of the substrates, that is to say with no clear effect of the steric and electronic parameters of the carboxylic acids (Table 4). As opposed to the use of Lewis acid catalysts like tris(pentafluorophenyl)borane ${ }^{7 d}$ or Gallium trichloride, ${ }^{7 g}$ the emission of hydrogen gas was not observed along our iridium catalysed reactions. The use of 2 equivalents of $1,1,3,3$ tetramethyldisiloxane (TMDS) does not always allow the formation of a single acetal. If the reaction selectivity depends on the molecular structure of the starting substrate, a rationalisation based on electronic or steric effects was not possible (Scheme 2, Schemes S1-S3, Figures S2-S5 in the Supporting Information). At this stage, further investigations on the reaction mechanism proved to be difficult.

\section{Conclusions}

To summarise, we have shown a versatile iridium(III) metallacycle catalyses effectively the reduction of various carbonyl and carboxylic acid derivatives with high yields at room temperature through hydrosilylation followed by desilylation or hydrolysis. The reaction of aldehydes and ketones, including sterically hindered substrates, results exclusively in alcohols. The hydrosilylation of more challenging compounds like carboxylic acid derivatives proceeds also well. Esters lead rapidly to either alcohols or ethers depending on the substrate basicity. Similarly, the nature of the carboxylic acid reagents controls also the outcome of the hydrosilylation reaction, either alcohols or aldehydes being formed. According our present and past works, the reactivity of iridium(III) metallacycles is promising in catalytic hydrosilylations of organic compounds.

\section{Experimental Section}

\section{General Procedure for the catalysis}

In a Schlenk tube, the reagent $(0.15 \mathrm{mmol}, 1$ eq. $)$ and iridium (III) catalyst (0.1-1 mol\%) are introduced. $\mathrm{NaBArF}_{24}$ salt $(0.2-2 \mathrm{~mol} \%)$ is then added in a glovebox. Under nitrogen, dichloromethane $(2 \mathrm{~mL}$, dry $)$ and the silane reagent $(0.18 \mathrm{mmol}, 1.2-3.0$ eq. $)$ are subsequently added by syringe and the reaction mixture is stirred at $25^{\circ} \mathrm{C}$ for a defined time (the Schlenk tube being closed under $\mathrm{N}_{2}$ ). In order to follow the advancement of the reaction, aliquots $(0.1 \mathrm{~mL})$ were taken at defined times. They were filtered over Celite and washed with dichloromethane $(3 \mathrm{~mL})$ before being analysed by GC. Alternatively, ${ }^{1} \mathrm{H}$ NMR analyses could be performed on the samples after their evaporation under vacuum. At the end of the hydrosilylation reaction, the crude reaction mixture is hydrolysed or desilylated following method A, B, C or D. Afterwards, the resulting solution is extracted with diethylether and washed with brine. Organic phases are then dried over $\mathrm{MgSO}_{4}$ and evaporated under vacuum. The resulting solid or oily residue is then purified by flash chromatography or preparative TLC.

Method A (for ketones 3f, 3k): After filtration of the crude mixture over a pad of silica subsequently washed with dichloromethane, solvents are evaporated under vacuum. The resulting crude mixture is then dissolved in methanol and an aqueous solution of hydrochloric acid $(1 \mathrm{M}, 1.5 \mathrm{~mL})$ is added. The resulting solution is vigorously stirred during 12 hours at room temperature. In some cases, a reaction time of 24 to 48 hours is necessary to recover products in high yields.

Method B (for ketones 3a, 3e, 3h, 3i, 3j): After filtration of the crude mixture over a pad of silica subsequently washed with dichloromethane, solvents are evaporated under vacuum. The resulting crude mixture is then dissolved in methanol and an aqueous solution of sodium hydroxide $(3 \mathrm{M}, 1.3 \mathrm{~mL})$ is added. The resulting solution is vigorously stirred during 12 hours at room temperature. In some 
cases, a reaction time of 24 to 48 hours is necessary to recover products in high yields.

Method C (for aldehydes and esters, for ketone $3 b, 3 c$, $3 \mathrm{~g})$ : After filtration of the crude mixture over a pad of silica subsequently washed with dichloromethane, solvents are evaporated under vacuum. The resulting crude mixture is then dissolved in distilled THF $(5 \mathrm{~mL})$ under nitrogen and one equivalent of tetrabutylammonium fluoride (TBAF, THF, $1 \mathrm{M}$ ) is added at room temperature. The resulting solution is vigorously stirred during 12 hours at room temperature. In some cases, a reaction time of 24 to 48 hours is necessary to recover products in high yields.

Method D (for carboxylic acids): After full-conversion, $100 \mu \mathrm{L}$ of water (1440 eq.) are added to the crude reaction mixture in dichloromethane and the resulting solution is vigorously stirred during 1 hour at room temperature. In some cases, a reaction time of 4 hours is necessary to recover products in high yields.

\section{Acknowledgements}

The University of Lille 1 and Région Hauts-de-France are acknowledged for PhD fellowships (Y. C; V.R.). The CNRS, the Chevreul Institute (FR 2638), the Ministère de l'Enseignement Supérieur et de la Recherche, the Région Hauts-de-France and the FEDER are acknowledged for supporting and funding partially this work. Mrs Céline Delabre (UCCS) is thanked for GC and GC-MS analyses. Mrs Nathalie Duhal, Mrs Céline Lenglart and Dr Mostafa Kouach (Univ. of Lille) are thanked for HRMS analyses.

Keywords: hydrosilylation; iridium; metallacycle; carbonyl derivatives; carboxylic acid derivatives.

[1] a) Modern Reduction Methods (Eds.: P. G. Andersson, I. J. Munslow), Wiley, New York, 2008; b) P. A. Dub, T. Ikariya, ACS Catal. 2012, 2 1718-1741; c) J. March in Advanced Organic Chemistry: Reactions, Mechanisms and Structures, Seventh Edition, Wiley-VCH, New-York, 2013.

[2] a) B. Marciniec, H. Maciejewski, C. Pietraszuk, P. Pawluć, in Hydrosilylation: A Comprehensive Review on Recent Advances, (Ed. B. Marciniec), Springer, Heidelberg, 2009; b) D. Addis, S. Das, K. Junge, M. Beller, Angew. Chem. 2011, 123, 6128-6135; Angew. Chem. Int. Ed. 2011, 50, 6004-6011; c) S. Werkmeister, K. Junge, M. Beller, Org Process Res. Dev. 2014, 18, 289-302; d) K. Revunova, G. I. Nikonov, Dalton Trans. 2015, 44, 840-866; e) J. Pesti, G. L. Larson, Org. Process Res. Dev. 2016, 20, 1164-1181; f) M. Oestreich, Angew. Chem 2016, 128, 504, Angew. Chem. Int. Ed. 2016, 55, 494-499; g) M. C. Lipke, A. L. Liberman-Martin, T. D. Tilley, Angew. Chem. 2017, 129, 2298-2332; Angew. Chem. Int. Ed. 2017, 56, 2260-2294.

[3] Hydrosilylation of aldehydes and ketones to alcohols using iridium catalysts: a) B. Marciniec, I. Kownacki in From Iridium Complexes in Organic Synthesis (Edited by L. A. Oro, C. Claver), Wiley-VCH Weinheim, 2009, 345-367; b) R. Malacea, R. Poli, E. Manoury, Coord Chem. Rev. 2010, 254, 729-752; c) S. Park, M. Brookhart, Organometallics 2010, 29, 6057-6064; d) E. Calimano, T. D. Tilley, Organometallics 2010, 29, 1680-1692; e) S. Kawabata, H. Tokura, C. Hiromu; H. Chiyojima, M. Okamoto, S. Sakaguchi, Adv. Synth. Catal. 2012, 354, 807-812; f) L. Chen, Y. Liu, G. Hou, H. Song, G. Zi, Inorg Chem. Commun. 2013, 29, 141-144; g) A. Petronilho, J. A. Woods, H. Mueller-Bunz, S. Bernhard, M. Albrecht, Chem. Eur. J. 2014, 20
15775-15784; h) K. Shinohara, S. Kawabata, H. Nakamura, Y. Manabe, S. Sakaguchi, Eur. J. Org. Chem. 2014, 5532-5539; i) Y. Manabe, K. Shinohara, H. Nakamura, H. Teramoto, S. Sakaguchi, J. Mol. Cat. A Chem. 2016, 421, 138-145.

[4] Hydrosilylation of aldehydes and ketones using coinage metals $(\mathrm{Cu}, \mathrm{Au}$ Ag): a) S. Díez-González, S. P. Nolan, Acc. Chem. Res. 2009, 41, 349 358; b) B. H. Lipshutz, Synlett 2009, 509-524; c) S. R. Roy, S. C. Sau S. K. Mandal, J. Org. Chem. 2014, 79, 9150-9160; d) E. Vasilikogiannaki, I. Titilas, C. Gryparis, A. Louka, I. N. Lykakis, M. Stratakis, Tetrahedron 2014, 70, 6106-6113; e) M. Teci, N. Lentz, E. Brenner, D. Matt, L. Toupet, Dalton Trans. 2015, 44, 13991-13998.

[5] Hydrosilylation of aldehydes and ketones using other first raw transition metals (Mn, Fe, Co, Ni): a) F. Jiang, D. Bézier, J.-B. Sortais, C. Darcel Adv. Synth. Catal. 2011, 353, 239-244; b) L. C. Misal Castro, D. Bézier, J.-B. Sortais, C. Darcel, Adv. Synth. Catal. 2011, 353, 1279-1284; c) E. Buitrago, F. Tinnis, H. Adolfsson, Adv. Synth. Catal. 2012, 354, 217222; d) D. Bézier, F. Jiang, T. Roisnel, J.-B. Sortais, C. Darcel, Eur. J. Inorg. Chem. 2012, 1333-1337; e) L. P. Bheeter, M. Henrion, L. Brelot, C. Darcel, M. J. Chetcuti, J.-B. Sortais, V. Ritleng, Adv. Synth. Catal. 2012, 354, 2619-2624; f) L. Postigo, B. Royo, Adv. Synth. Catal. 2012, 354, 2613-2618; g) J. Zheng, C. Darcel, J.-B. Sortais, Catal. Sci. Technol. 2013, 3, 81-84; h) A. J. Ruddy, C. M. Kelly, S. M. Crawford, C A. Wheaton, O. L. Sydora, B. L. Small, M. Stradiotto, L. Turculet, Organometallics 2013, 32, 5581-5588; i) Q. Niu, H. Sun, X. Li, H. F. Klein, U. Florke, Organometallics 2013, 32, 5235-5238; j) V. K. Chidara G. Du, Organometallics 2013, 32, 5034-5037; k) V. César, L. C. Misal Castro, T. Dombray, J.-B. Sortais, C. Darcel, S. Labat, K. Miqueu, J. M. Sotiropoulos, R. Brousses, N. Lugan, G. Lavigne, Organometallics 2013, 32, 4643-4655; I) S. J. Kraft, R. H. Sanchez, A. S. Hock, ACS Catalysis 2013, 3, 826-830; m) J. Zheng, S. Elangovan, D. A. Valyaev, R. Brousses, V. César, J.-B. Sortais, C. Darcel, N. Lugan, G. Lavigne, Adv. Synth. Catal. 2014, 356, 1093-1097; n) H. Zhao, H. Sun, X. Li, Organometallics 2014, 33, 3535-3539; o) Z. Zuo, H. Sun, L. Wang, X Li, Dalton Transactions 2014, 43, 11716-11722; p) D. Kumar, A. P. Prakasham, L. P. Bheeter, J.-B. Sortais, M. Gangwar, T. Roisnel, A. C Kalita, C. Darcel, P. Ghosh, J. Organomet. Chem. 2014, 762, 81-87; q) H. Zhou, H. Sun, S. Zhang, X. Li, Organometallics 2015, 34, 1479 1486 ; r) F. S. Wekesa, R. Arias-Ugarte, L. Kong, Z. Sumner, G. P. McGovern, M. Findlater, Organometallics 2015, 34, 5051-5056; s) M. A. Nesbit, D. L. M. Suess, J. C. Peters, Organometallics 2015, 34, 4741 4752; t) C. Ghosh, T. K. Mukhopadhyay, M. Flores, T. L. Groy, R. J. Trovitch, Inorg. Chem. 2015, 54, 10398-10406; u) B. Xue, H. Sun, X. Li, RSC Adv. 2015, 5, 52000-52006; v) S. Huang, H. Zhao, X. Li, L. Wang, H. Sun, RSC Adv. 2015, 5, 15660-15667; v) Y. Wei, S.-X. Liu, H. Mueller-Bunz, M. Albrecht, ACS Catalysis 2016, 6, 8192-8200; x) T. C. Jung, G. Argouarch, P. van de Weghe, Catal. Commun. 2016, 78, 52 54; y) X. Yu, F. Zhu, D. Bu, H. Lei, RSC Adv. 2017, 7, 15321-15329; z) B. Xue, H. Sun, Q. Niu, X. Li, O. Fuhr, D. Fenske, Catal. Commun. 2017, 94, 23-28.

[6] Hydrosilylation of hindered ketones to alcohols: a) B. Tao, G. C. Fu, Angew. Chem. Int. Ed. 2002, 41, 3842-3894; Angew. Chem. 2002, 114 4048-4050; b) D. A. Evans, F. E. Michael, J. S. Tedrow, K. R. Campos J. Am. Chem. Soc. 2003, 125, 3534-3543; c) B. H. Lipshutz, C. C Caires, P. Kuipers, W. Chrisman, Org. Lett. 2003, 5, 3085-3088; d) S Díez-González, H. Kaur, F. K. Zinn, E. D. Stevens, S. P. Nolan, J. Org .Chem. 2005, 70, 4784-4796; e) S. Díez-González, N. M. Scott, S P. Nolan, Organometallics 2006, 25, 2355-2358; f) G. Hamasaka, A. Ochida, K. Hara, M. Sawamura, Angew. Chem. Int. Ed. 2007, 46, 5381 5383; Angew. Chem. 2007, 119, 5477-5479; g) T. Fujihara, K. Semba, J. Terao, Y. Tsuji, Angew. Chem. Int. Ed. 2010, 49, 1472-1476, Angew. Chem. 2010, 122, 1514-1518.

[7] Hydrosilylation of carboxylic acids: a) N. Sakai, K. Kawana, R. Ikeda, Y. Nakaike, T. Konakahara, Eur. J. Org. Chem. 2011, 3178-3183; b) K. Miyamoto, Y. Motoyama, H. Nagashima, Chem. Lett. 2012, 41, 229231 ; c) L. C. Misal Castro, Hao Li, J.-B. Sortais, C. Darcel, Chem. 
Commun. 2012, 48, 10514-10516; d) D. Bezier, S. Park, M. Brookhart, Org. Lett. 2013, 15, 496-499; e) J. Zheng, S. Chevance, C. Darcel, J.-B. Sortais, Chem. Commun. 2013, 49, 10010-10012; f) T. Fujihara, C. Cong, J. Terao, Y. Tsuji, Adv. Synth. Catal. 2013, 355, 3420-3424; g) N Sakai, T. Nakajima, S. Yoneda, T. Konakahara, Y. Ogiwara, J. Org. Chem. 2014, 79, 10619-10623; h) T. V. Q. Nguyen, W.-J. Yoo, S. Kobayashi, Adv. Synth. Catal. 2016, 358, 452-458.

[8] Hydrosilylation of esters to alcohols: a) S. C. Berk, K. A. Kreutzer, S. L. Buchwald, J. Am. Chem. Soc. 1991, 113, 5093-5095; b) S. C. Berk, S. L. Buchwald, J. Org. Chem. 1992, 57, 3751-3753; c) D. J. Parks, W. E. Piers, J. Am. Chem. Soc. 1996, 118, 9440-9441; d) H. Mimoun, J. Org Chem. 1999, 64, 2582-2589; e) T. Ohta, M. Kamiya, M. Nobutomo, K. Kusui, I. Furukawa, Bull. Chem. Soc. Jpn. 2005, 78, 1856-1861; f) A. C Fernandes, C. C. Romão, J. Mol. Cat. A: Chem. 2006, 253, 96-98; g) S Das, K. Möller, K. Junge, M. Beller, Chem. Eur. J. 2011, 17, 7414-7417 h) L. Pehlivan, E. Métay, S. Laval, W. Dayoub, D. Delbrayelle, G. Mignani, M. Lemaire, Eur. J. Org. Chem. 2011, 7400-7406; i) D. Bézier G. T. Venkanna, L. C. Misal Castro, J. Zheng, T. Roisnel, J.-B. Sortais C. Darcel, Adv. Synth. Catal. 2012, 354, 1879-1884; j) K. Junge, B Wendt, S. Zhou, M. Beller, Eur. J. Org. Chem. 2013, 2061-2065; k) J. A. Fernández-Salas, S. Manzini, S. P. Nolan, Chem. Commun. 2013, 49, 9758-9760; I) O. O. Kovalenko, H. Adolfsson, Chem. Eur. J. 2015, 21, 2785-2788.

[9] Hydrosilylation of esters to ethers: a) Z. Mao, B. T. Gregg, A. R. Cutler, J. Am. Chem. Soc. 1995, 117, 10139-10140; b) M. C. Hansen, X. Verdaguer, S. L. Buchwald, J. Org. Chem. 1998, 63, 2360-2361; c) N Sakai, T. Moriya, T. Konakahara, J. Org. Chem. 2007, 72, 5920-5922 d) S. Das, Y. Li, K. Junge, M. Beller, Chem. Commun. 2012, 48, 10742-10744.

[10] a) M. J. Fernandez, L. A. Oro, B. R. Manzano, J. Mol. Cat. 1988, 45, 715; b) R. S. Tanke, R. H. Crabtree, J. Am. Chem. Soc. 1990, 112 7984-7989; c) C.-H. Jun, R. H. Crabtree, J. Organomet. Chem. 1993 447, 177-187; d) E. Mas-Marza, M. Poyatos, M. Sanau, E. Peris, Inorg Chem. 2004, 43, 2213-2219; e) Y. Miyake, E. Isomura, M. Iyoda, Chem Lett. 2006, 35, 836-837; f) C. Vicent, M. Viciano, E. Mas-Marza, M Sanau, E. Peris, Organometallics 2006, 25, 3713-3720; g) J. Cipot, R. McDonald, M. J. Ferguson, G. Schatte, M. Stradiotto, Organometallics 2007, 26, 594-608; h) V. S. Sridevi, W. Y. Fan, W. K. Leong, Organometallics 2007, 26, 1157-1160; i) E. Calimano, T. Don Tilley, J. Am. Chem. Soc., 2008, 130, 9226-9227; j) A. Zanardi, E. Peris, J. A Mata, New J. Chem. 2008, 32, 120-126; k) C. Vicent, M. Viciano, E. Mas-Marza, M. Sanau; E. Peris, Organometallics 2006, 25, 3713-3720 I) E. Calimano, T. Don Tilley, J. Am. Chem. Soc. 2009, 131, 1116111173; m) M. Iglesias, M. Perez-Nicolas, P. J. Sanz Miguel, V. Polo, F. J. Fernadez-Alvarez, J. J. Perez-Torrente, L. A. Oro, Chem. Commun. 2012, 48, 9480-9482; n) M. Iglesias, P. J. Sanz Miguel, V. Polo, F. J. Fernadez-Alvarez, J. J. Perez-Torrente, L. A. Oro, Chem. Eur. J. 2013 19, 17559-17566.

[11] a) Y. Motoyama, M. Aoki, N. Takaoka, R. Aoto, H. Nagashima, Chem Commun. 2009, 1574-1576; b) S. Park, M. Brookhart, J. Am. Chem.
Soc., 2012, 134, 640-653; c) C. Cheng, M. Brookhart, J. Am. Chem. Soc. 2012, 134, 11304-11307; d) C. Cheng, M. Brookhart, Angew. Chem. 2012, 124, 9556-9558, Angew. Chem. Int. Ed. 2012, 51, 94229424

[12] a) R. Lalrempuia, M. Iglesias, V. Polo, P. J. Sanz Miguel, F. J. Fernández-Alvarez, J. J. Pérez-Torrente, L. A. Oro, Angew. Chem. 2012, 124, 12996-12999, Angew. Chem. Int. Ed. 2012, 51, 12824 12827; b) S. Park, D. Bézier, M. Brookhart, J. Am. Chem. Soc. 2012 134, 11404-11407; c) E. A. Jaseer, M. N. Akhtar, M. Osman, A. AlShammari, H. B. Oladipo, K. Garces, F. J. Fernandez-Alvarez, S. AlKhattaf, L. A. Oro, Catal. Sci. Technol. 2015, 5, 274-279, d) A. Julián, E. A. Jaseer, K. Garcés, F. J. Fernández-Alvarez, P. García-Orduña, F. J. Lahoza, L. A. Oro, Catal. Sci. Technol. 2016, 6, 4410-4417.

[13] a) Y. Corre, W. Iali, M. Hamdaoui, X. Trivelli, J.-P. Djukic, F. AgbossouNiedercorn, C. Michon, Catal. Sci. Technol. 2015, 5, 1452-1458; b) C Michon, K. Maclntyre, Y. Corre, F. Agbossou-Niedercorn ChemCatChem 2016, 8, 1755-1762; c) Y. Corre, C. Werlé, L. BrelotKarmazin, J.-P. Djukic, F. Agbossou-Niedercorn, C. Michon, J. Mol. Catal. A: Chem. 2016, 423, 256-263; d) Y. Corre, V. Rysak, F. Capet, J.-P. Djukic, F. Agbossou-Niedercorn, C. Michon, Chem. Eur. J. 2016, 22, 14036-14041; e) Y. Corre, X. Trivelli, F. Capet, J.-P. Djukic, F. Agbossou-Niedercorn, C. Michon, ChemCatChem 2017, 9, 2009-2017.

[14] J. Yang, P. S. White, M. Brookhart, J. Am. Chem. Soc. 2008, 130, 17509-17518.

[15] a) C. T. Chang, C. L. Chen, Y. H. Liu, S. M. Peng, P. T. Chou, S. T. Liu, Inorg. Chem. 2006, 45, 7590-7592; b) C. C. Chang, B. S. Liao, S. T. Liu, Synlett 2007, 18, 283-287.

[16] a) M. Oestreich, J. Hermeke, J. Mohr, Chem. Soc. Rev. 2015, 44, 2202-2220; b) M. Iglesias, F. J. Fernández-Alvarez, L. A. Oro ChemCatChem 2014, 6, 2486-2489; c) T. T. Metsänen, P. Hrobárik, H. F. T. Klare, M. Kaupp, M. Oestreich, J. Am. Chem. Soc. 2014, 136, 6912-6915; d) W. Wang, P. Gu, Y. Wang, H. Wei, Organometallics 2014, 33, 847-857; e) M. Iglesias, P. J. Sanz-Miguel, V. Polo, F. J Fernández-Alvarez, J. J. Pérez-Torrente, L. A. Oro, Chem. Eur. J. 2013, 19, 17559-17566.

[17] M. Hamdaoui, M. Ney, V. Sarda, L. Karmazin, C. Bailly, N. Sieffert, S. Dohm, A. Hansen, S. Grimme. J.-P. Djukic, Organometallics 2016, 35 2207-2223.

[18] a) C. Scheeren, F. Maasarani, A. Hijazi, J.-P. Djukic, M. Pfeffer, S. D. Zaric, X.-F. LeGoff, L. Ricard, Organometallics 2007, 26, 3336-3345; b) Y. Hu, L. Li, A. P. Shaw, J. R. Norton, W. Sattler, Y. Rong, Organometallics 2012, 31, 5058-5064.

[19] a) J. B. Lambert, S. Zhang, C. L. Stern, J. C. Huffman, Science 1993 260, 1917-1918; b) S. J. Connelly, W. Kaminsky, D. M. Heinekey, Organometallics 2013, 32, 7478-7481; c) M. Nava, C. A. Reed, Organometallics 2011, 30, 4798-4800; d) S. P. Hoffmann, T. Kato, F. S. Tham, C. A. Reed, Chem. Commun. 2006, 767-759. 
